Chelonian Conservation and Biology, 2008, 7(1): 136-141 C) 2008 Chelonian Research Foundation

\section{Dietary Observations on the Asian Softshell Turtle (Amyda cartilaginea) from Sarawak, Malaysian Borneo}

\author{
Karen A. Jensen ${ }^{1}$ and IndraneIL Das ${ }^{1}$ \\ ${ }^{1}$ Institute of Biodiversity and Environmental Conservation, \\ Universiti Malaysia Sarawak, 94300, Kota Samarahan, Sarawak, \\ Malaysia [kitti_jensen@yahoo.com;idas@ibec.unimas.my]
}

Abstract. - We examined the diet of Amyda cartilaginea from 2 localities in Sarawak: Loagan Bunut National Park and Balai Ringin. The most commonly found items in stomach contents, when using percentage frequency of occurrence, were plant material (77\%) and unknown vertebrate parts $(55 \%)$. Fecal analysis indicated similar results: plant material $(100 \%)$, unknown vertebrate parts $(84 \%)$, fish $(69 \%)$, and unknown arthropods $(62 \%)$. Results indicate that A. cartilaginea is an opportunistic omnivore.

The Asian softshell turtle (Amyda cartilaginea) is a large, locally widespread trionychid from the lowlands of tropical Southeast Asia (Fig. 1). Its currently known range is from northeast India; Myanmar; Thailand; Laos; Vietnam; Cambodia; Malaysia; Singapore; Indonesia; and the islands of Borneo, Sumatra, Java, Lombok, Sulawesi; and some of the smaller associated islands (Ernst and Barbour 1989; Cox et al. 1998; Lim and Das 1999; Pawar and Choudhury 2000). In Sarawak, on Malaysian Borneo, A. cartilaginea inhabits a variety of freshwater types, including clear or muddy rivers, lowland peat swamps, ponds, and irrigation canals (Lim and Das 1999).

Little is known about the natural history of $A$. cartilaginea, and information on its diet is largely anecdotal. As part of a larger ecological study of freshwater turtles of Sarawak, information on the diet of this species was obtained from stomach contents and feces. The primary study area was Loagan Bunut National Park (coordinates for the park headquarters are at lat $03^{\circ} 44^{\prime} \mathrm{N}$, long $114^{\circ} 09^{\prime} 17^{\prime \prime} \mathrm{E}$; datum wgs 84 ), located in the northern part of Sarawak. Field work was concentrated at the park (description of area and its herpetofauna in Das and Jensen 2006). In addition, 2 visits were made to Balai Ringin (lat $01^{\circ} 03^{\prime} \mathrm{N}$, long $110^{\circ} 45^{\prime} \mathrm{E}$ ), a fishing village ca. 2-hour drive from Kuching, Sarawak's capital city. Both sites are located within peat swamp forests. Loagan Bunut National Park contains the only freshwater floodplain lake in Sarawak (Sayer 1991), and encompasses $650 \mathrm{ha}^{2}$ at its maximum level. The lake is completely dry during periods of prolonged drought. The lake dries up annually, between
3 and 6 times, usually in the months of February, May, and June.

Methods. - The study described here was conducted between May 2004 and April 2005. A variety of collecting techniques, as previously described for freshwater turtles in the literature, were attempted to see which was the most effective for capturing A. cartilaginea. Hoop traps, commonly used to catch freshwater turtles in the Western hemisphere (Frazer et al. 1990; Legler 1960; Vogt 1980) were used. Native hoop traps, called $b u b u$, were also used, in addition to another local fishing device called a selembau, which comprised a special system of scoops and nets attached to long poles. The device is stretched across a river or stream, scooping up whatever comes into contact with it (Fig. 2). Manual capture, otherwise known as muddling (Cagle 1942), was an effective albeit laborintensive method of capturing softshell turtles. The technique involves wading through streams and probing areas of sand or mud and among roots with a stick, hands, or feet and could only be accomplished during times of low water level.

Dietary analysis was conducted based on both stomach and fecal samples of living specimens. Dissection of stomachs to examine contents was not possible in this study because all turtles are protected under the Sarawak Wildlife Protection Ordinance (Sarawak Government Gazette 1998). Within 1 hour after returning from the field, stomachs were flushed by using the method developed by Legler (1977), which incorporated the modifications of Fields et al. (2000). Turtles were kept in plastic basins, which were $60 \mathrm{~cm}$ in diameter and $30 \mathrm{~cm}$ in depth, with some water. They were kept under observation until they defecated, usually 24 to 48 hours, and were released afterward at the place of capture. Each sample (stomach content or fecal matter) was washed in water by using a mesh strainer of $0.2-\mathrm{mm}$ mesh size. These samples were immediately preserved in $70 \%$ ethanol for study.

Contents of the stomach and fecal samples were examined separately for each turtle. Types of food were sorted under low magnification by using an Olympus SZX9 dissecting microscope. The presence of each dietary group was recorded to the lowest identifiable taxon, typically to ordinal level of classification. In addition, 2 categories were used: unknown arthropods and unknown vertebrates. Any unidentifiable part of an insect or any other arthropod, i.e., wing, claw, etc., was grouped into the first category. The unknown vertebrates category represented any part known to be from a vertebrate, i.e., bone fragments, but unclassifiable further. The volume of each kind was determined by the displacement of water in either a 5 -mL or 25-mL graduated cylinder, as described by Moll and Legler (1971). Descriptive analysis of data that pertained to contents of stomachs and fecal samples were expressed in 2 ways: 